\title{
Feminism, Argumentation and Coalescence ${ }^{1}$
}

\author{
MICHAEL A. GILBERT York University
}

Keywords: Agreement, argumentation, coalescence, feminism, Gilligan, Andrea Nye, rationality, Tannen.

\begin{abstract}
This essay begins with a critique of the Critical-Logical model dominant in contemporary argumentation theory. The concerns raised stem primarily from considerations brought by several feminist thinkers including Carol Gilligan, Karen Warren, Deborah Tannen and, most especially, Andrea Nye. It is argued that, in light of these considerations, and concerns of essentialism or non-essentialism notwithstanding, that the Critical-Logical model is liable to dis-enfranchise a significant part of the population with regard to modes and styles of reasoning. The solution is found in coalescent reasoning, an approach to argumentation that focuses on finding agreement rather than emphasizing disagreement and criticism.
\end{abstract}

\section{Introduction}

The teaching of Critical Thinking is a large industry with an eager and generally satisfied consumer audience. The reason for this is that students learn techniques they did not know previously that are immediately useful in all of their courses. What they learn are the skills of criticizing, analysing and finding fault with an argument. They learn how to find errors in reasoning and logic, how to identify fallacies, and generally, how to collect grounds for rejecting a position. For many, though by no means all of these students, the ability to examine an argument critically, find its faults and flaws remains a skill that they can apply across the board. They can, after all, begin immediately by using it in their other courses, and the many who make that magical connection do so and keep doing so. In short, they acquire a whole approach to reasoning and thinking that they find very successful. This is especially true in their current academic environment and later in the industries it feeds, primarily business and government.

A good part of the approach students acquire through critical thinking means that they can better construct and understand positions as well as criticize and analyse. But tied in with the techniques and skills is a wide ranging set of values. The flavour of these values is evidenced in the very name of the subject. 'Critical thinking', has within it the idea 'critic' as in to criticize and, at the very least, to judge and assess. What one should do when one reasons, and certainly when one argues, is to be critical. There are other, more specific, values as well. These values, argumentative, social and moral, include a conception of reality that accepts a fairly rigorous sense of the true/false, wrong/right dichotomies, the holding dear of the convince/persuade distinction, and at least some version of the Natural Light Theory. The convince/ persuade distinction holds that the proper way to argue appeals exclusively to reason, logic, and the mind. When an individual changes her mind as a result of the application of these methods she will be said to have been "convinced'. ${ }^{2}$ Persuasion, on the other hand, appeals to emotion, self-interest, and the body. Being persuaded as opposed to convinced is to have changed one's mind by dint of lesser, fallacious or rationally inappropriate means. The Natural Light Theory is the view that the "true" or "best' position will be the one to survive a properly conducted rational competitive inquiry. 
I will call this nexus of values, techniques and attitudes the Critical-Logical Model [hereafter C-L]. According to the C-L the best examples of reasoning are linear and careful. Extraneous material such as emotional content, power relationships and the social consequences of the argument are separated from its text or transcript in order that the argument itself can be examined. Discovery and justification are two very separate processes on the C-L view, facts are things we can get our hands on, and the politics, social outlook or personal history, i.e., the situation, of the arguers is almost always irrelevant to the evaluation of the argument. Information is carefully separated into that which is relevant and may be adduced as evidence or reasons, and that which is not and must be ignored or put aside while the argument is being examined.

In what follows I want to examine critical reasoning in particular, and the C-L model in general with regard to the assumptions made and the values inherent in the approach. The motivation for this inquiry is a concurrence of my own work and objections brought against the $\mathrm{C}-\mathrm{L}$ tradition by several feminist commentators. In the remainder of this section I briefly introduce the notion of 'coalescence', clarify several key assumptions, and establish that the issue is essentially a moral one. I then, in part II, discuss the problem generally by reviewing a number of important concepts introduced by feminist thinkers in the past ten to fifteen years. This is followed by a discussion of the work of three scholars whose writing speaks strongly, if not always directly, to the concerns of Argumentation Theory. Special attention is devoted to Andrea Nye's Words of Power (1990).

Part III is my attempt to bring together the thinking that has preceded in an integrated programme for critical reasoning. Here I more fully discuss the notion of 'coalescent communication,' and argue that we can teach critical reasoning that embraces inclusion, agreement and connectedness. Coalescent communication posits agreement as the goal of successful argumentation wherein the ob- ject is to identify not what is wrong with an argument, but what are the points of agreement and disagreement. The emphasis is on minimizing disagreement by carefully examining what crucially requires disagreement as opposed to what is merely an inessential accompaniment of the opposed position. Furthermore, coalescent argumentation views an argument not as an isolated and autonomous artifact, but as a linguistic representative for a position-cluster of attitudes, beliefs, feelings and intuitions. In this regard, coalescent argumentation is an attitude correlated to a practice. (In this essay the attitude is introduced, but the practice is not fully articulated here.)

'Coalescence' means combining two things into one whole or bringing separate things together. When applied to argument I intend it to indicate an approach that attempts to merge disparate views as much as possible. This operates primarily by taking into account the wide variety of human communicative modes that are involved in a position-cluster. These include the traditional C$L$ rational mode as well as the emotional, intuitive, physical, situational and historical modes. By becoming aware of all of these contributors to an individual's adoption of a position we can understand it more fully, and, as a result, find the aspects with which we can agree, sympathize, or, at the very least, understand. These last three characteristics are essential to coalescent argumentation because they support connection by achieving recognition. Understanding a position-cluster encourages the identification of the dispute partners with each other and with the two positions at issue. It does not, of course, entail agreement: nothing does or will. What it does do is underscore the commonality of the goals and desires held by each participant. This respect and recognition, this identification of each arguer with the other, means that we are far more liable to find alternative solutions, middle grounds, or new positions that respect the core concerns of the original positions. This is the ideal end result of coalescent argumentation. 
Several words of caution. The choices laid out here can be viewed as involving a total choice of paradigms, or, at the least, to use Warren's (1988) terminology, conceptual frameworks. As a result, the adjudication process is complex: which mode or tradition shall be used as the criteria for acceptance? Which form(s) of arguing are to be permitted? I have been led in this by two factors. First, my own work (Gilbert, 1994) is strongly based on the importance of eclecticism in reasoning. Secondly, the C-L Principle of Charity instructs us to give as much as we can to an opponent in the interest of logical faimess, but also to prevent an easy getaway. Consequently, where I have had to choose I have chosen to take as wide a latitude as possible. I hope that, at the very minimum, if I cannot effect consensus, then at least the key issues and divergences may be properly aired and exposed.

A second waming concerns a controversial issue within the feminist philosophical community. Some writers hold that there are essential differences between men and women that can be categorized in various ways. For these essentialists the historical problem has been not so much the identification of feminine characteristics, as the negative value placed on those characteristics. Barring truly misogynist traits such as emptyheadedness, essentialists accept that women are more caring, nurturing, intuitive, sensitive and so on, and identify the difficulties as lying within a system that denigrates these particular abilities and denies their relevance to power and authority. The problem, then, is not with women's essential nature, but with the socio-political power structure's attitude toward that nature. The post-essentialists, on the other hand, have great difficulty with this approach. First, they do not see that there are any characteristics held by men which cannot be held by women, and certainly none which make a moral or political difference. Secondly, any set of characteristics identified as essentially female must, perforce, apply to a particular social, cultural and economic group of women, and not, as the essentialists would have it, to a conception of 'woman' that is prior to concrete differentiation. ${ }^{3}$

The authors to be discussed below attack the traditional Critical-Logical reasoning process on the grounds that women (by and large) communicate differently than men, hold different values than men, and prioritize differently than men. There is, however, nothing in my use of their writings which depends on the essentialist nature of their positions. This is because the concern here is with communicative practices, and most authors seem willing to accept that for whatever reasons there are identifiable gender differences in modes of communicating that are generalizable. One caveat to this is that the groups studied and referred to by these authors tend to be, by and large, western, white and middle-class. There are no grounds, therefore, for supposing that these same communicative differences would apply to all the diverse economic and socio-cultural groups that exist within the world. Moreover, it is quite likely that many males have some or all of the characteristics described as feminine and that many women have some or all characteristics described as masculine. Individual and group socialization, personality, training and personal proclivity are all factors that form the matrix of a given person's communicative logic. Nonetheless, the profile of a communicator as portrayed by the writers to be discussed below identifies a model that will be labelled 'feminist' or 'female'. It should, however, be understood that no stand is being taken here on the truth of essentialism. To the contrary, insofar as coalescent argumentation requires men to incorporate techniques and attitudes identified by the authors to be discussed as feminine, the opposite must be true.

There are two final tasks necessary before going further. The first is an explication of what I mean by 'dominant' in the expression 'dominant form of reasoning', and the second involves establishing the moral nature of the feminist claim.

What I mean by claiming that the C-L mode of reasoning is the dominant mode is 
that the C-L mode is to thinking as the $O x$ ford English Dictionary is to language. One can, of course, speak as one likes for many purposes, but in formal business, legal or other situations one may not. In Canada the $O E D$ is the legal arbiter of English spelling and meaning. When dealing with contracts, constitutions, laws, legal decisions, or academic tracts, one must basically use the official language of the realm. Stray too far, go beyond negotiated national or cultural variations, and it is no longer official English.

Reasoning is similar. There is a dominant and, for all intents and purposes, official way to reason. It is true that there is no one book like the $O E D$ that has legal status; but there is a body of work and continuity of history crystallized in texts as old as Aristotle or as current as the most recent edition of Copi or Kahane. In the official places, government and business reports, editorials and legal decisions, university seminars and colloquia, it is this mode that must be used. A trial is halted when someone begins to cry. Emotional reactions are excluded from business decisions. Persistent belief in a "defeated" argument is unreasonable. Believing without "concrete" evidence is childish. Facts are what matter, not feelings or intuitions. Evidence provided must meet strict requirements. It is in this sense that the C-L mode of reasoning is dominant and that others are subordinate and kept in their place. That place may be various. It may include the home, large subgroups of the population, informal conversation, different cultures, and so on. The point, however, is that the subordinate mode is not permitted into those realms that involve power, and, in particular, they are largely precluded from influencing key decisions in government, business, and academia. Robin Lakoff puts it this way, "Men's language is the language of the powerful. It is meant to be direct, clear, succinct, as would be expected of those who need not fear giving offence, who need not worry about the risks of responsibility.... Women's language developed as a way of surviving and even flourishing without control over economic, physical, or social reality" (1990, p. 205). This has resulted in conversational and argumentative moves that are often seen by some scholars as different for the genders. When women's techniques are used, they can easily be stifled by a comment such as, 'That's all very interesting, but can we please keep to the facts (or issues or problem or agenda)?" This is what I mean by dominant.

There is nothing, in and of itself, that is morally wrong with declaring a particular mode of reasoning or argument as subordinate to a dominant mode and, therefore, limiting its applicability. In the United States the exclusion of religious visions, personal insights or bodily threats from a court of law is a social and political decision based on long historical precedent. In Iran, to cite a different case, religious insight and interpretation play an important role in the courts. The acceptance that one mode of reasoning or proof is better or more reliable is, in the end, a combination of practical, political and moral influences deeply effected by ancient trends in social power and intellectual history. Every society will have a dominant mode, the question is whether it is fair and just given the precepts and ideals of that society. Native Canadians, for example, have been arguing that their justice system should be independent of federal and provincial systems just because the moral values, metaphysical and political beliefs of their cultures are fundamentally different from that of the dominant group. Consequently, the kinds of arguments, evidence, and modes of reasoning brought forward in official contexts that are respected within the culture are radically or substantially different.

Recently, some feminist writers have been arguing that there are substantial and fundamental differences between the modes of reasoning and the social and political interests and requirements of women as opposed to men. The effect of these differences is to put women at a disadvantage politically, economically and socially. The difficulty is that unlike native Canadians, separation is not really an option, (just as aboriginal women who are concerned with their own status 
within the larger group cannot independently separate). Consequently, if the C-L mode of arguing/communicating does oppress or, (at least) disadvantage women, then the current debate is a complex moral one, and not merely a call for eclecticism. A group is suffering discrimination and power denial because its natural (or usual or preferred) mode of communication and/or reasoning is not sufficiently mainstream to be easily recognized by the dominant $\mathrm{C}-\mathrm{L}$ mode. ${ }^{4}$ As a result the 'official' venues do not make allowance or inclusion for the kind of reasoning and worldview many women require. It is worth remembering that the right to be tried in one's own native language where nuance, vernacular and subtlety can both be used and understood is considered to be of vital importance to minority language groups.

Consequently, the issue as to whether or not female modes of reasoning and patterns of thought ought to be included in official contexts is a moral one. It involves the unfair limitation of the power of one group by another. Moreover, that limitation is not based on real need, but rather on perceived differences that themselves are only rendered significant by the lights of the dominant framework itself. As a result, if it can be shown that 1] there are significant differences in reasoning modes between some men and some women, and 2] those women's modes are generally not respected, permitted, or heard as freely and easily as the dominant men's, then there must be a moral onus on the part of argumentation theorists, especially in their normative role of argument judges and critical thinking teachers, to see that such modes are incorporated into mainstream teaching, research and consideration.

\section{The Position of Some Feminists}

I will now turn to an examination of the details of the position propounded by the several feminists to be reviewed here. The several authors will be separated into two categories. The first category will include Carol Gilligan, Deborah Tannen, and Karen Warren, while Andrea Nye holds sole possession of the second.

With the exception of Nye, most of the criticisms of the $C-L$ tradition have been fairly mild. After all, their authors have grown up in that tradition and have been trained and inculcated in it. Regardless of gender, one can barely get a $\mathrm{Ph} . \mathrm{D}$. in philosophy (or any academic discipline) without having been through the rigours (such as they are) of formal and informal logic. Yet, there is a mounting sense of disquiet, of urging, that concepts important to women are ignored and/or denigrated. These include connectedness or attachment, concern or inclusion, and agreement or consensus. While some writers view reliance on these characteristics as essentially feminine or as defining of female-ness, others see them as traits that women embrace or are attached to for straightforwardly sociohistorical reasons. Virtually all feminists, however, see the traits as valuable, important, and often trivialized by the male establishment. Code allows that, "Many feminists are convinced that traits associated with essential femininity responsibility, trust, and a finely tuned intuitive capacity are epistemically valuable" (1991). Regardless of how these characteristics come to be more prevalent in one gender, they recur in the literature with sufficient consistency so as to come to any reader's attention. Moreover, as several have relevance to modes of argumentation and communication, and specifically to coalescent argumentation, their examination provides valuable insights.

Connectedness, the first of the key characteristics to be examined, covers the notion that we are all affected by actions of diverse persons and not just ourselves. What an individual does can have, of course, an impact on himself, but will also have an impact on other persons more or less distant from him. Such actions can include events that have obvious consequences, or trivial events that multiply by virtue of their cumulative effect. An example of the former would be a corpo- 
rate decision to change working hours that explicitly takes into account the needs of employees tied to daycare routines. The latter might be exemplified by various ecological concerns such as protecting the biosphere to prevent cancer causing UV rays. In other words, the consequences of a position to a large variety of people are relevant to evaluating the position. The core of the notion, however, is not the truism that our actions have consequences, but rather the attitude that those connected to us are ever present and are considered as a matter of course. The idea is that we exist within a web of connections and attachments, not as separate and autonomous individuals making our own way. Rather than distinct units in competition with each other, there is, if you will, an enormous extended family populating the globe. Gilligan, discussed below, has much to say about this concept.

Simply accepting that one's personal and corporate actions have effects on others is not sufficient to mark a major change in argumentative outlook. In addition, one is required to have concern for those to whom one is connected. Where the notion of connectedness determines that an individual's 'family' is larger than one might imagine, concern dictates that we care about that family: one cares about those to whom one is connected. This has a dramatic impact, for example, on the notion of relevance. On the $\mathrm{C}-\mathrm{L}$ model the sphere of relevance of an issue may be much narrower than on a feminist model. What and with whom one is concerned can change as the model is altered.

The C-L model holds a number of presuppositions that are in direct conflict with a feminist approach. The first is that arguments have winners and losers, and, as a corollary, that arguments are, or should be, about claims representing positions, which themselves are true or false. (I do not mean to suggest that every argument actually has a psychological winner and a loser, but that the general outlook is that there is or can be one even if the parties involved are not themselves aware of it.) A feminist model, on the other hand, gen- erally is more consensually oriented. That is, the focus is more on finding agreement than on eliminating the opposing position. At the end of an argument the partners to the dispute should not (necessarily) have abandoned one position and adopted the other, but might rather have found a mutual ground to share. Abandoning the idea that argument is a zerosum game allows for a basis of negotiation not oriented toward simply moving on, but built on a genuine concern for one's partners needs, wants, attitudes and beliefs. Argument, on this model, is among persons, not between theories. This attitude puts a premium on understanding why a dispute partner holds a given position insofar as the motivation for maintaining a position can often shed light on the way through an impásse. That is, we cannot always separate what people believe from why, when, and how.

Carol Gilligan, in her landmark book, In a Different Voice, is not specifically concerned with the notion of argument (1982). Rather, her focus is the gross lack of attention paid to the profound differences between the respective world outlooks of the genders, and how such ignorance has had a negative impact on research about and views concerning women. Gilligan allows that the observations she makes apply generally to women, but that the distinctions are not absolute (p. 2). She describes her concern as being the separation of distinct 'modes of thought', and wants us to understand nothing less than that men and women interpret the world differently. ${ }^{5}$

Gilligan uses two key terms that may be used to encapsulate the essential differences between the genders. These are 'connectedness' and 'separation' (p. 8), and they describe the differences in the way men and women relate to the world and, most especially, its inhabitants. Put simply, women are far more focused on their attachments to others, their place in the web of human relationships, and their connectedness to the people with whom they interact. Men, on the other hand, have independence from others, their status in the hierarchy of individuals, and their separation from control and obliga- 
tion as paramount loci. One can believe these gender differences result from a male's as opposed to a female's need to separate himself in order to establish his gender identity, or the immediate inculcation of societal values, or the overweening impact of testosterone and estrogen, or (more likely) a combination of these and yet other factors. One might even believe that they are not gender differences at all, but people differences that merely happen to be more prevalent among the female population within a specific culture. In any case, Gilligan's terms serve well to capture the distinction, and, insofar as she is talking about ways in which we think and interpret the world, the connection to argumentation is not tenuous but concrete and direct. "From the different dynamics of separation and attachment in their gender identity formation through the divergence of identity and intimacy that marks their experience in adolescent years, male and female voices typically speak of the importance of different truths, the former of the role of separation as it defines and empowers the self, the latter of the ongoing process of attachment that creates and sustains human community" (p. 156).

One concrete difference in the approach to argumentation can be seen when we examine the ways in which the boys and girls Gilligan studied play. Boys have no compunction about having raging arguments concerning rule violations or judgment calls involving intense, often legalistic argument, shouting, name-calling, accusations, threats and recriminations. Very importantly, however, the game does not stop, while for girls, on the other hand, a quarrel often means the end of the game. Gilligan interprets this as meaning that to the girls the rules are just not as important as the feelings of the players. "Rather than elaborating a system of rules for resolving disputes, girls subordinated the continuation of the game to the continuation of relationships" (p. 10). The connection to argumentation and critical thinking is obvious. When we teach the Critical-Logical model we are very rule focused. The emphasis is on what is said and how to analyse the words. On the C-L model it is the rules and the words that are paramount, not the partners to the dispute. The feminist model, on the other hand, denies the separability of persons, rules, words and positions.

Male competitiveness and aggression, long taken as the norm (p. 42), also influences argument to a great degree. As a result, it is only natural that arguments result in a winner, in one person who is best and/or whose theory is best. According to the theorists examined here women's outlook is more web-like than hierarchical. The paradigm is connection: we are all and always connected. In terms of how one proceeds in an argument, the impact is great. "Thus the images of hierarchy and web inform different modes of assertion and response: [for men] the wish to be alone at the top and the consequent fear that others will get too close; [for women] the wish to be at the centre of connection and the consequent fear of being too far out on the edge (p. 62)." In other words, aggression and competition are liable to mean that a woman will be isolated and find herself removed or peripheral to the familial and social web through which she views the world. On this female perspective, vanquishing an opponent is liable to involve a separation of the opponent from the victor thereby entailing a loss of connection. 'Winning' on Gilligan's view would involve not alienating a dispute partner. (Vide also, Tronto, p. 658.) Concern with the person with whom one argues, as much if not more than with the ideas presented, will alter one's approach to a dispute. This is an ideology which will speak to every conceivable aspect of argument.

The point to be taken from Gilligan is not just that men are more aggressive than women and, therefore, their styles of argument will be different. This is very likely true, even though other factors can heavily influence argument and conversational style (Tannen, 1984). What is even more important than style is focus: according to Gilligan women will be more concerned with the details, dynamics and effects of the process. Who a partner in a dispute is, what connections and con- 
cerns she has, and why the issues are important to her are every bit as vital, if not more so, than the precise representation of premisses and conclusions. These things, the actual individual circumstances of the particular case, the feelings of those involved, the effects on others, the motivations become part of the argument. On the C-L model such factors are not necessarily ruled out of court, but they are put to one side as contextual, pragmatic, or emotional aspects not to be confused with the actual argument.

Deborah Tannen concurs with Gilligan on the essential differences in the way the genders approach communication and, therefore, argument. A man sees himself "... as an individual in a hierarchical social order in which he [is] either one-up or one-down. In this world conversations are negotiations in which people try to achieve and maintain the upper hand if they can, and protect themselves from others' attempts to put them down and push them around. Life, then, is a contest, a struggle to preserve independence and avoid failure" (pp. 24-25). Women, on the other hand, see themselves "... as an individual in a network of connections. In this world conversations are negotiations for closeness in which people try to seek and give confirmation and support and to reach consensus" (p. 25).

Some of Tannen's points concern questions of style as, for example, women's tendency to use personal experience (p. 92) or their attention to details (p. 115), both habits many men have difficulty with. Even these points of style, however, stem from the varying outlooks of the genders. For women, personal experience is often more important than abstract considerations that have little to do with real people or real situations. In her defense of Gilligan, Marilyn Friedman concurs: "The key issue is the sensitivity and responsiveness to another person's emotional states, individuating differences, specific uniqueness, and whole particularity" (p. 106). Attention to detail, Tannen writes, "shows caring and creates involvement.... Because women are concerned first and foremost with establishing intimacy, they value the telling of details" (p. 115). In other words, we cannot separate style and substance.

For both women and men there is more going on in a given conversation than the words. But often what goes on is different. For many of the men Tannen and Gilligan studied there is a constant interplay of status. There is a continual flow of meta-messages that determine hierarchy and involve subtle yet significant conflicts. This is true in ordinary conversation and even more so in argument which is directly conflictual. When talking about problems, for example, women tend to sympathize and recognize the problem as in, "Yes, I know what you mean, a similar thing happened to me." Men, on the other hand, are far more likely to offer a solution as in, "Well, in that case why don't you..." Empathy relies on connection and similarity, while offering a solution is hierarchical insofar as one has an answer to a problem the original speaker could not solve (pp. 51-52).

Given these distinct core outlooks it is hardly surprising that there are different approaches to conflict. More men than women enjoy a 'good argument' (Tannen, p. 150). From early on and in many socio-cultural arenas women are taught and find it natural to be conflict avoiders, to seek agreement and consensus. For many men, arguing without being committed or as devil's advocate is the intellectual equivalent of schoolyard roughhousing. Just like the tumult of wrestling and tackling, arguing can be very aggressive and apparently antagonistic, but also exhilarating and downright enjoyable to those to whom it is considered play. Given that the great majority of critical reasoning texts have been written by men and/or in the Critical-Logical tradition, it is not surprising that such a high value is placed on the results (if not the joy) of conflict. It is also not surprising that they have as assumptions such separation oriented notions as the Natural Light Theory [NLT] and the convince/persuade distinction. The NLT is separation oriented because it supposes that there is a right and wrong or true and false that is the sort of thing that can be determined in an argument. The convince/ 
persuade distinction, on the other hand, supposes that we can create categories and separate arguments insofar as they do or do not contain elements foreign to logical reasoning. Considered in this light, there is a sense in which the assumptions inherent in the $\mathrm{C}-\mathrm{L}$ approach are, at core, 'masculine'. They derive from a long tradition and history during most of which female input was neither desired or permitted. One last quote from Tannen:

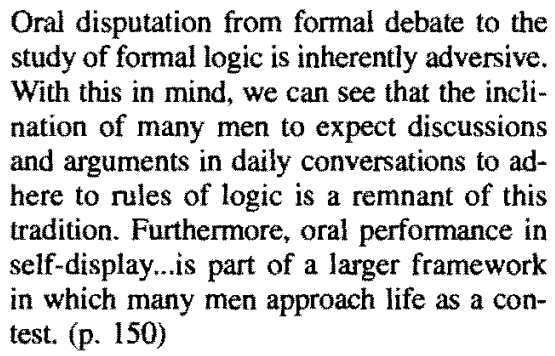

In the end, Tannen urges us to pay attention to 'genderlect'. It is not so much that one communicative mode must take over, as it is that there has to be room for both. Arguing in 'contest-mode' must not be the only legitimate path. Understanding the opposite gender, she claims, is analogous to understanding a different dialect in a language. If we are to communicate effectively, if we are to understand nuance, meta-messages, context and truly comprehend the communication we must enter into the dialect. We must try to understand the customs and engage in the practices as much as possible if we are trying to foster communication. This conclusion is very much in keeping with the concept of attachment. Tannen seeks not to exclude or judge, but to explain and integrate. Lakoff points out that while it is likely not attainable, "The ideal would be for both sexes to move their way of communicating closer to some middle ground"(p. 207). If the genders are to integrate and utilize the separate approaches understanding is every bit as important as respect. If either are missing the project is doomed.
Not all writers accept the underlying goodwill supposed by Tannen. In her article, "Critical Thinking and Feminism", Karen Warren (1988) describes the C-L mode and the conceptual framework on which contemporary critical thinking is largely based as 'oppressive' (p.32). A conceptual framework is "... a set of basic beliefs, values, attitudes, and assumptions which explain, shape, and reflect our view of ourselves and our world" (ibid.). So the sorts of outlooks and core premisses described by Gilligan and Tannen form an important component of a typical male's conceptual framework. ${ }^{6}$ Three characteristics typically mark out a framework as oppressive. First, it is 'value-hierarchical', that is, it holds that certain things have greater value than other things (e.g., reason over emotion,) and that the more valued things are 'higher'. Secondly, there is a reliance on a strong notion of exclusive disjunction. Something is, for example, right or wrong, emotional or logical, valid or invalid, without much room for negotiation. This is a highly 'separation' view as opposed to the alternative, being inclusive and complementary, which is much more 'connection' oriented. Finally, an oppressive framework "gives rise to a logic of domination" (p. 32). This means that the framework permits one group to view themselves as superior to another group and justifies subordination of that other inferior group.

All science and all human activity takes place within a conceptual framework, ergo, argument and reasoning do as well. Warren argues that the Critical-Logical tradition is oppressive insofar as the assumptions on which it is based are essentially male and preclude female concerns and modes of reasoning. What is viewed as important by a given framework, e.g., the definition of 'argument' or the importance of context, involves unquestioned assumptions integral to the framework (p. 36). Core notions such as the meaning of 'impartiality' can vary dramatically depending on whether one takes an attachment or separation view. For the C-L theorist, being impartial means listening to an ar- 
gument and judging its worth without undue bias. But, Warren points out that, "from a feminist point of view, impartiality requires inclusiveness" (p. 39). That is, being impartial does not mean being fair about which belief is rejected, rather it means incorporating and including as much as possible of other people's views and beliefs.

If Warren is correct, or even partially correct, then the $\mathrm{C}-\mathrm{L}$ tradition has within it certain assumptions and prerequisites which are inimically intolerant of the reasoning and communicative modes of a large portion of the population. ${ }^{7}$ As practically all contemporary $\mathrm{C}-\mathrm{L}$ theorists personally espouse a liberal view the idea that the framework itself is, on the most generous view, exclusive, and, on the worst, inherently oppressive, is alarming. And, yet, if we consider Gilligan's and Tannen's work it is difficult, if not impossible, not to lend some credence to Warren's claim. The C-L approach simply does not take the values and practices of women into account. It upholds the logicality and linearity that underlies male reasoning and values, while not incorporating the notions of context and inclusiveness that are arguably significant components of female reasoning. Warren concludes, "It may be that critical thinking must be feminist if it is truly to be what it purports to be, viz., reasonable and reflective activity aimed at deciding what to do or believe" (p. 41).

Logic, we are taught in 101, has nothing to do with content. In presenting logic we may begin with actual sentences referring to various exemplary persons, e.g., "Peter bought a car," or, "Rhoda went to the party with Quincy", but these references to people, parties and their doings are inexorably eliminated in place of sentential variables and truth-functional constants. This is because, to quote Andrea Nye in her (1990) controversial history of logic, Words of Power, "All truth has the same structure and it is for logic to reveal it" (p. 3). As a result logic has nothing to do with anything, and the logician works in a context-less, rarefied realm. "He sheds his intentions, fears, humiliations, resentments; all of his natural life is only dead skin that falls away to reveal the hard bone of thought itself. The impulses that drove him to logic, the examples he chooses to illustrate his points, all the contingent transitory dross of his daily life, are irrelevant to his logic, which is what has to be thought, what cannot not be thought, what cannot change or die" (p. 3). But on an attachment ideology, on a feminist model, such a conception of logic does not really make sense. "Logic is a human invention, although logicians may deny it, and it must speak of something, speak of ambitions, fears, hopes, disappointments, despairs. Logic must refer to the objects of a common world. Not only must it speak of something, but it must speak to someone and thereby institute the relationships in which communication is possible" (p. 4). And, "In my view, there is no one Logic..., but only men and logics, and the substance of these logics, as of any written or spoken language, are material and historically specific relations between men, between men and women, and between them and objects of human concern" (p. 5).

Nye's indictment of logic is thoroughgoing and complete. Her book is an analysis of the history of logic from Parmenides through Frege from her interpretation of a feminist perspective. A review of this work is relevant here for two reasons. First, critical reasoning has its roots in logic. The core notions of 'argument', 'premiss', 'conclusion', 'true' and 'false' can all be traced back, ultimately, to logic. Secondly, most of the time Nye uses 'logic' in a broad sense that includes modes of reasoning as well as formal systems. That is to say, the rules of the current logic dictate what sorts of reasoning patterns, responses, and concerns are deemed legitimate. And, to begin with, Nye objects to just such a delineation of proper and improper reasoning. As logic became a subject, a discipline, it was, of course, restricted to those who learned to reason properly, those who had power and permission to study and examine philosophical and logical subjects. One who did not know logic simply did not know how to carry on a proper rational discussion. "It was not 
just women who were excluded from rational discussion [in ancient Greece]. Slaves, nonGreek barbarians, as well as the masses of low-born Greek artisans and workers who could not be expected to regulate their feelings and desires in the ways required by logic were also barred from logical thought" ( $p$. 37). Since women were not familiar with the rules, "...she could be accused of lack of rigor and lack of understanding of the categories of rational expression" (ibid.).

It is important to notice that the large majority of the population, both female and male, were excluded from the realms of rational thought. Instruction in the methods of proper logical procedure were limited to the ruling and educated classes. One must wonder if it was the logic that made this so, or the social institutions that separated those who learn from those who do not. In other words, is the bias intrinsic to the system of logic, or is it the accessibility of elite system that is the culprit? ${ }^{8}$ Nye speaks about the Sophists and of Plato's conservative war against them (p. 31 ), but they apparently do not figure in her conception as an ameliorating influence. This theme continues in her discussion of Aristotle. The emergence of the syllogism with its high level of abstraction, mathematicized use of variables and connectives, made logical thinking into a highly technical subject. "Greek rationality, exemplified in the syllogism, was a mark of the superiority of Greek culture. Trained in logic, graduates of Aristotle's Lyceum proceeded to posts in newly colonized areas, confident of their superiority and their ability to govern..... Women, slaves, workers, and conquered people, all those who participate in dialectical contests, were expected to accept the superior reasoning of the masters" (p. 48). The difficulty, of course, is that the training in this highly technical resource was not available to the groups listed by Nye.

A key point is raised here. To what extent is the problem the inherent unfriendliness of logic to women (if, indeed, that be so), and to what extent is it the fact of a ruling class laying down the lingua franca? Lakoff concurs with Nye when she argues that the choice of a male mode of communication was made in order to exclude women. "No one decides what communication is intrinsically 'logical,' then notices that women don't do it, and therefore rationally determines that women are illogical. It's rather the reverse. The dominant group first notices the ways in which the nondominant differ from themselves.... Then they decide that there must be some principled difference between men and women to explain the discrepancy" (p. 203). Nye says on page 2 that when she took her required logic course only men went on to upper-level logic courses. My own experience in an urban multi-cultural university belies this. In fact, I have largely found a sufficiently close fiftyfifty mark at all levels of logic I have taught so as to make it unremarkable. No, I believe the important point Nye raises in her section on Aristotle is the creation of an official mode of reasoning that became common in the courts, politics and institutions of power. It is the exclusion of alternative modes that creates the inequity, that permits the oppression of those for whom it is not a first or core language. This includes the sorts of edicts made by logic that we all take for granted, e.g., "Only statements that can be true or false form the premisses and conclusions of arguments" (Nye, p. 67). Again, what happens to the person/group/gender/race that does not think or work in those terms? Their statements become inappropriate for logic. And, when 'being logical' is the official way to be, it means they are liable to become disenfranchised. When logic is used as a means of silencing, it stops being a thing of rarefied beauty and becomes a tool of oppression. (Vide, for example, Nye's discussion of Abelard and Heloise (pp. 97-100).)

Nye's analysis of the history of logic is troubling. Sometimes she seems to be describing an unstoppable monolith specifically designed by the male autocracy to oppress and silence women and all others who might compete for power. There have been, she allows, opposers: Thrasymachus (p. 49), the Sophists (p. 31), John of Salis- 
bury (p. 82). But Nye does not take them as representative of a desire for connectedness that is sufficient to excise the devil of logic. And eventually that devil was incarnated in Frege. With the Begriffschrift we have the move from using language to express logic, to the assumption that language and communication depend on logic. Without proper logic there is no truth. When Frege eliminates language altogether, when we reach the point where structure and content become two completely separable things, when truth is only reliably expressed in tautological metaphor, then for Nye, logic no longer has anything to do with people, and, therefore, with communication. In C-L terms, this is the formal analogue of the notion that an argument can be studied out of context.

Nye makes an excellent case for viewing the history of logic as a progression that steadily eliminates humanity, connected-ness and human interaction. But she herself is not sufficiently looking for connections. Her history is stopped at Frege, and her anger at the emptiness of his system, his (according to Nye) Nazi sympathies, and the separation of philosophical responsibility from personal responsibility is palpable. There is barely a mention of Russell, nothing substantive, and certainly nothing about his going to prison rather than to war. And what of Tarski who left his homeland for the U.S.A. to avoid the Nazis? In the preface to his Introduction to Logic, originally published during World War II, he offers the following explanation of his devotion to the subject.

I have no illusions that the development of logical thought... will have a very essential effect upon the process of the nomalization of human relationships; but I do believe that the wider diffusion of the knowledge of logic may contribute positively to the acceleration of this process. For, on the one hand, by making the meaning of concepts precise and uniform...logic leads to the possibility of better understanding among those who have the will for it. And, on the other hand, by perfecting and sharpening the tools of thought, it makes men more critical and thus makes less likely their being misled by all the pseudo-reasonings to which they are incessantly exposed in various parts of the world today. (1965, p. XV)

The vision he saw, and, I believe, shared with Russell, was, rightly or wrongly, a noble and caring one. Logic, for these men, would take us out of the quagmire of confusion and permit clear communication. If people can learn not to believe false pseudo-reasoning and reject totalitarian ideology, then the world would indeed be a better place. Why, for them, was this important? Because they saw the inability of people from different cultures to communicate as obstacles to peace and well-being. They could not fathom what causes the incomprehensible madness that is war. Surely, no one wants to go to war. And, if they still do, then it must be a breakdown of communication, and, if so, having a pure comprehensible language might prevent such madness. It was hardly their agenda to oppress.

Why would a man or woman pursue logic? First of all, because it is a beautiful and elegant system providing one with rules and procedures for non-conflictual discourse. It provides avenues and means for maintaining communication within bounds that permit it to proceed. As long as communication can proceed, violence might be averted. If men can come together and reason according to agreed upon procedures, then life might proceed peaceably. Of course, I use the term 'men' intentionally. As holders of power, as decision-makers, it is men who must be held most responsible. But saying that individual logicians had lofty motivations does not mean that there is no reason for change. On the contrary. First of all, logic hasn't worked. There are as many wars and injustices now as ever. Secondly, the claim being made that alteration is required on moral grounds is, to me, compelling. No, my regret is that Nye never considered the motives she holds so important. Frege's life is laid bare before us, but no mention is made of Leibniz' dream of 
new knowledge for humankind. Leibniz, like Russell, dreamed of oppressing no one.

Why stop with Frege? Why not with Lukasiewcz? An alleged Nazi sympathizer, but one who first introduced a logic that denied the Law of The Excluded Middle. Why not mention L.E.J. Brouwer's investigations into three-valued logic? Why begin so far back and then halt at a time when reaction to religion and mysticism had spurred great efforts in logic and science? A great deal has changed since Frege. Certainly Logicism, and, for all practical purposes, Logical Positivism, died sudden deaths when Gödel's Incompleteness Theorem came out. Subsequent to that, Wittgenstein published the Investigations, and, as a result, formal logic became a mere branch of mathematics. Around the same time Paul Lorenzen developed dialogical systems of logic. Since then we have witnessed Ordinary Language Philosophy and our own Argumentation Theory. I would like to know if Nye sees these theories as moving from separation toward connection. She also commits the same sin of omission of which she accuses Quine (p. 2), by not even mentioning a single woman logician. There is no reference at all to BarcanMarcus, Stebbing, Anscombe, Haack or Barth to name but a few. In any case their contributions are not to be trusted: "The feminist logician speaks from a script in which the master always wins" (p. 180). Indeed, Nye seems to think not just that the aridity of Fregean logic is inhospitable to women, but that it is anathema. In order to understand this one must read carefully the concluding chapter of Nye's book.

There are two main things wrong with logic and critical thinking as we know it today. The first and overarching problem is the forced de-contextualization of argument and truth. Nye writes about the difference between 'reading' and 'analyzing'. Reading involves the holistic understanding of a position, approach or story. It attempts to view what is said, argued or told in light of its context, its genesis, its im- portance to who says it and its significance to whom it is said. When we read the emphasis is on understanding; when we analyse the emphasis is on judging. Analysis takes us away from the who and the why, 'beyond' the words and the feelings, needs and desires to where we can examine the truth in isolation. We can test it for logical truth, inspect it for validity, and then decide if it is worthy of consideration. Only, what is said, what is meant, can be lost in that process. And, if Gilligan, Tannen and other feminist researchers are even partially correct, then when many women speak their priorities of relevance and importance are very different from men's. For many people, women especially, attempting to understand and evaluate communication that is not situated is unnatural and borders on the meaningless. Nye "believe[s] that all human communication, including logic, is motivated. I believe that...people when they speak or write always want something and hope for something with passion and concern, even when part of that passion and concern is to deny it" (p. 174). And again, "...words themselves, no matter how cleverly arranged, cannot tell the truth; they must have meaning and to have meaning they must be spoken by someone somewhere on some occasion" (p. 175).

The second sin of logic was its adoption by the ruling male elite as the official mode of reasoning and communication. Had it remained a recondite and isolated academic pursuit it might have escaped unnoticed. But it did not. Logic became the official way to communicate in the presence of men, in the corridors of power, and in the classrooms of philosophers. "In the place of the human community was founded the segregation that logic instituted, between an illogical feminine household charged with the administration of slave labour and reproduction, and a male polis with law courts, assemblies, and magistrates in which rational discourse prevailed. Logic reinforced the boundaries of that separation" (p. 178). In other words, the ruling 
class first determined what it was to be rational, then determined that anyone who was not rational did not have to be heard.

It would be easy to hyperbolise Nye, to analyse and critically dismiss her claims. But it would only be easy if I were to do so relying upon the very assumptions and framework she is criticizing. Nye does not really hold logic responsible for all the sins of history: "Logic cannot be credited with beginning the oppression of slaves, women, under-classes, or subject peoples, or even with playing the major role in maintaining these oppressions" (p. 79). And, yet, logic allowed men to ignore women and others because of the way they speak, because they did not take to or know a language that was kept from them. The oppression comes from the exclusion, and those excluded include anyone who cannot comprehend that structure is independent of and far more important than content. One can respond that this is not true: all attention to structure does is allow us to classify certain highly defined argument forms as reliable (i.e., formally valid,) and others as not. Or, less formally, it allows us to examine arguments in isolation from their context in order to determine their power and separate their persuasibility from their logical content. The promise of critical thinking is great: "Logic will teach you to be critical, to learn not to accept an opinion as true without demanding an argument, it will teach you to defend your position with force. We must learn to think logically, learn to demand support for claims, catch incorrect inferences, search for inconsistency" (p. 181).

And what is wrong, after all, with demanding support for claims? Why should the Critical-Logical tradition apologize for instructing students, all students, that opinions require arguments? Because when an approach is official, when it is presented as the only way to proceed, or as the only correct way to proceed, when the bureaucratic establishment in government, business and academe will brook no deviation, then its power is too great. People are not heard and their communications dismissed because they do not 'make sense' according to the $\mathrm{C}-\mathrm{L}$ mode. They are set aside because they are emotional, fallacious, mystical, based on feelings, argued incoherently or illogically. In this sense it is not women who are illogical, but logic that is illogical because it is illogical to expect every person and every communication to fit into a specific pattern, be it formal or informal, in order for it to be acceptable.

\section{Coalescent Argumentation}

Coalescent argumentation rests on two major assumptions. It begins with the premiss that all communication, and most especially argumentative communication, is situated. That is, the view, belief or position put forward is being held by a person, and it holds that understanding the relationship between that person and the view is vital and integral to pursuing a judicious argument. This includes, necessarily, the simple comprehension of the position itself, but goes beyond that toward seeing a position in relation to the person who holds it. No position or belief is held in isolation, and therefore the larger picture of beliefs, needs, wants and feelings surrounding the issue must be considered in order to properly understand and, eventually, assess it.

No one will argue the basic premiss that words are often not meant to be taken literally. Grice's notion of conversational implicature, or some such related concept, instructs us that the context may alter the meaning of the actual sounds uttered (Grice, 1975). On the one hand, the words may be used colloquially or metaphorically: when someone says, "He's between a rock and a hard place," we do not look for him squashed up against a large boulder. Individual words in the language are famous for dependence on context. The word 'great', for example, can mean "wonderful" or "awful" depending on the context: "Great, I found ten dollars," or, "Great, my car won't start." Similarly, people who regularly interact frequently rely on shared 
information and knowledge of previous or ongoing discussions (Willard, 1989, p. 42 ff.; Legge, 1992). An outsider not privy to the history of the argument might have as much difficulty deciphering a conversation as a non-native speaker trying to decode a colloquialism. In order to understand what someone is saying we have to know who they are, why they are saying what they are saying, and what they hope to accomplish as a result of saying it.

Secondly, coalescent argumentation begins with an emphasis on agreement. The thrust is not to determine how to eliminate or criticize or defeat the presented view, but how to understand, incorporate, respect and move toward consensus. Whereas the first core assumption derives from a truism that is insufficiently respected, viz., that all meaning is context dependent, this second assumption clearly involves the invoking of a value. In addition, this assumption directly challenges the Natural Light Theory [NLT] which holds that competing theories that clash in the arena of reason result in the truer (or better) emerging victorious. The central idea of the NLT is that, ceteris paribus, the view that is the most cogent, well-reasoned and best evidenced will withstand all assaults while the lesser theory will not. Now I am not claiming that many people believe wholeheartedly in the NLT. For one thing, as stated above it is both false and misleading. False because two many false theories have survived (and still survive) far too long. Examples include racism, sexism, and nationalism as found in articulated views. Misleading because, at any rate, too much is carried in the 'ceteris paribus' clause. Arguers are never equal: too much depends on what is thought of at the moment as well as the social politics of the situation. Nonetheless, the attitude underlying the NLT does permeate critical reasoning in the $\mathrm{C}-\mathrm{L}$ tradition.

Moving from a critical/disagreement based approach to a coalescent/agreement based one is not a simple matter. The change is pervasive, and affects the very way one goes about argumentation. One does not begin by listening to an argument and deciding where it is weak, what can be attacked, and how to best undermine it. Rather, one first begins by recognizing that the argument presented represents a richer, situated position that can best be understood as a cluster of beliefs, attitudes, feelings and intuitions. Further, this positioncluster has a history attached to the individual offering it, and is associated with a set of goals, problems, needs and desires. The first objective of an arguer should be to understand the position-cluster being offered. By understanding a dispute partner's position (and, of course, one's own), in a rich way one is able to separate those components which are essential from those which are not. In addition, one can more easily identify the problem (if there is one) that is motivating the disagreement, and thereby consider alternate solutions to the initial one being proposed. On this model, one asks not, "What can I disagree with?" but, "What must I disagree with?" Similarly, the focus is not on what can be attacked, but on how two apparently divergent positions can be reconciled.

If one were forced to choose one item that could be identified as the essence of coalescent argumentation it would be the idea that arguments are presented only by people, and that as such they should be considered as flags or markers for human situations. That is, an argument for something indicates an individual who wants, needs or desires some end. The reasons actually presented in the argument may or may not relate to the motivating considerations, the historical antecedents, or the rational judgment process connected to the asserted claim. But the argument, considered in the traditional C-L sense, is best understood as the mere tip of an iceberg that represents all these various facets. Arguments have conclusions or claims, but people who present arguments have goals, and the arguments they present are intended to attain those goals. We may, in being 
properly critical toward a presented argument, defeat it, or eliminate it, or cause its withdrawal, but by the same token we may well have not dealt with the far more important and vital issue of satisfying a legitimate goal or deflecting or redirecting an illegitimate one.

In the $\mathrm{C}$ - $\mathrm{L}$ tradition an argument is generally assumed to be a conclusion and one or more premisses. It is an artifact of communication, something that has, allowing for enthymematic characteristics, been uttered. And there certainly is a specialized area which analyses, dissects, and examines these artifacts as sui generis items: they can, for example, be valid or invalid, sound or unsound, fallacious or acceptable. In and of itself there is nothing wrong with such analytical tools, the difficulties arise as a result of overemphasizing or misunderstanding the role of such formalisms. The first error occurs when the impression is given, explicitly or implicitly, that such an analysis covers what is essentially going on in an argument. That is, if the analysis purports to describe the most important aspects of an argument, then it misses too much. Secondly, when the claim is made that 'reasoning' is or should be an exercise constituted by rules that determine acceptable and unacceptable CRCs, and that all other modes of persuasion, dissensual communication, analysis or comprehension are either not reasoning or are somehow inferior, then again, the definition is too restrictive.

Arguments are best considered as interactions taking place in a dissensual framework. Within that framework one is liable to come across premiss-conclusion complexes, but they may be the least important aspect of the process. Arguments in this sense can also be construed as stories. Nye, for example, talks about reading as opposed to analyzing. The former takes into account the situation, context and history of the argument, while the latter attends only to the visible concrete aspects. In other words, the argument is considered with all its connections intact, much as a story must be read with attention given to the characters, setting and plot. According to Tannen and Gilligan women use story to communicate because it is holistic and describes and takes for granted the connectedness of those involved. One must know the circumstances to understand. Code speaks of the importance of novels as locating "...moral analyses and deliberations in textured, detailed situations in which a reader can, vicariously, position and reposition herself to understand some of the implications for people's lives of moral decisions, attitudes and actions" (1991, p. 168). Moreover, in the vast period of time when women were excluded from Academe, oral traditions of storytelling, and later fiction, carried women's philosophical and other observations. Tannen (1990) quotes over twenty selections of fiction to illustrate, describe, and underscore her points. Gilligan both uses stories told to her and stories elicited from subjects to demarcate the gender differences with which she is concerned. But the $\mathrm{C}-\mathrm{L}$ tradition denies the relevance of story to the adjudication of an argument. Such ancillary considerations are traditionally ruled out of court before they are even considered.

Changing the emphasis in critical reasoning courses from analysis to understanding, like changing the terminology from conclusion to goal and premiss to motivation, would emphasize the contextual nature of argumentation as well as underscore that the desired result is not victory by one party, but agreement between two parties. We can certainly keep classical premiss-conclusion arguments and the precise analytical models that pertain to them, but we do the field and our students a disservice when we pretend that these things are the crucial components of argumentative communication. Moreover, the authors discussed above make a reasonable case for supposing that the style of argument fostered by the C-L tradition is preponderantly male, and that this disparity places an unfair obstacle in the path of 
those women who feel themselves excluded from the official arenas where one is required to argue 'reasonably'.

Were it not so inherently embedded in our various curricula and textbooks, I would urge dropping the term 'critical reasoning' altogether. In its stead we could use something like, 'considered reasoning,' 'judicious comprehension,' or, of course 'coalescent argumentation'. The problem is that the term 'critical' in the expression 'critical reasoning' is overpowering. First of all, it is negative. Insofar as one can, one should criticize the offered reasoning. Not understand it, sympathize with it, elaborate on it, share it, but find fault with it. Secondly, there is the sense that all good reasoning is of this kind. All sound, mature, sophisticated, academic, serious reasoning eschews emotion, intuition and situation, and concentrates on the real content the explicit words and essential implicit assumptions that can be identified, isolated and criticized in the argument qua artifact. The assumption is that this particular mode of analysis is what constitutes proper reasoning, and that all other forms of data interpretation and consideration are not proper reasoning. And this is crucial not because this definition excludes other modes from being reasoning, but because reasoning has a total grip on power and by excluding non$C$ - $L$ modes, those who rely upon them are left powerless. It is not so much that logical (formal or informal) relationships must be denied as that other relationships must be affirmed. And that affirmation should bear with it whatever honorifics are required to grant them official status.

\section{Concluding Remarks}

Critical Reasoning has been an important part of philosophy since its inception. In its early forms it involved Socrates teaching wealthy young Athenians the finer points of disputation by putting them through their paces. Later, the Sophists added a short-lived democratic note which did not re-emerge for many centuries. Through the middle ages logic and rhetoric were studied and taught to the educated religious and civil elite, practically all of whom were men. The modes and styles that evolved were naturally those most suited to its developers and progenitors, and for a very long time, were kept from the masses as something every bit as inappropriate as knowing how to read. As education expanded so did critical reasoning, until the twentieth century where it has become a major industry.

If we pay particular attention to the latter part of this century we can identify a desire on the part of various writers to emphasize the contextual nature of critical reasoning. Examples that might have previously been drawn from Ovid are now taken from current newspapers, books and other media. One way to think of this is as a diminution of the emphasis on abstraction, and more of one on situation. The suggestions made by myself and drawn from the feminist scholars considered above can be seen as a progression or continuation of this line.

The first aim is to foster a form of reasoning that is not wholly linear and dedicated to finding fault in order to win (or, if not to win, then to eliminate the presented argument). But that does not mean we should focus entirely on emotions, intuitions, personal history, and situation. Rather, it is the respect of these as tools in the evaluation of an argument and in the discussion of a position. It is the determination of whether an argument involving such information is or is not worthy of a reply. Rational analysis in the C-L tradition is only objectionable insofar as it is taken to be all that is involved in the judicious comprehension of an argument. By this I mean that the considerations leading to a decision to accept or reject a position, in whole or in part, can and ought involve discussion and information from these 'non-logical' or 'non-rational' realms. How to go about this in an informed and intelligent way should be the subject matter of the courses we teach on reasoning and argumentation, as well as research by argumentation theorists. 
The second aim is the focus on agreement, on consensus, on attachment, on inclusion. This is perhaps the most crucial aspect. For, if we focus on understanding rather then finding fault, then the inclusion of a broader range of information is a natural consequence. This requires a more embracing, less competitive approach to argumentation. One in which it is taken for granted that positions involve many aspects of human behaviour, are never simple, and almost always involve some right, some wrong, some good and some bad. As a result, the position must be explored and understood in a comprehensive way as a prelude to finding a basis for consensus. This is the goal; it may not always be possible. There are fanatics on every issue and they are highly represented among both genders, so agreement, consensus, or a coalescent approach may not always be possible. But the aim is some kind of agreement, on searching for mutually satisfying outcomes if those provided are not acceptable.
Coalescent argumentation describes an attitude to dissensual communication that involves utilization of a wide range of information, both classically acceptable and not. It supposes that positions inhere in people and not in their words, and therefore includes knowledge about people, their emotions, intuitions and motivations as relevant. It also has a focus on consensual agreement as the ideal outcome of argument, wherein the parties involved leave with a deeper understanding of each other, their opposer's position, and their own position. Further, there is an acknowledgment of the complexity of any issue worth discussing, and a recognition that no single view has, in all likelihood, the truth or right answer. Given all this, coalescent argumentation describes a continuation within argumentation theory and critical reasoning toward a greater respect for situational relevance, feminist considerations of differences in thought and communication processes, and the individual as a locus of feelings, thoughts, beliefs and intuitions.

\section{Notes}

I I would like to thank Prof. Leslie Green, Prof. Else Barth, and the Informal Logic referees for helpful comments on this essay. All errors are unquestionably my own.

$z \quad$ Rather than use the sometimes cumbersome 'his/her' jargon, I will alternate genders in various examples and so on.

3 Code, in her excellent What Can She Know? (1991), has a thorough discussion of this issue. See esp., ch. 3. Also of interest is Hawkesworth (1987).

4 The sense of 'natural' used here need not refer to essential biological attributes, but to such less deterministic factors such as socialization, comfort zones or inclinations.

5 While Gilligan's work has received much positive attention and has brought to light numerous hidden sexist presumptions in psychology and sociology, she has been taken to task for not recognizing that her own conclusions apply primarily to the socio-economic groups studied. It is not clear, in other words, if all of her conclusions apply to females and males not in white, western, middle-class contexts. Her observations, however, are certainly important in understanding communication and argumentation, and may well shed light on other more disparate groups by opening up the idea that the genders often require distinct studies which presume distinct values. This same proviso, that study groups are culturally restricted, applies to Tannen as well. A thorough discussion of this issue will be found in Signs, $(1986,11: 2)$.

6 It is worth noting that a conceptual framework is not necessarily an essential set of characterisitcs pertaining to a particular gender. 
7 Even if one supposes that a significant portion of women are comfortable with the $\mathrm{C}-\mathrm{L}$ mode, there will still be many for whom it is not the main or prime or most significant means of communication, Moreover, added to this group will be (at least) a significant minority of males who share that perspective. Ergo, on any accounting a large portion of the population is left, if not in the cold, then at lest in the chill.

${ }^{8}$ It is interesting to note that a case can be made for claiming that the same state of affairs exists in present times. Uneducated or differently educated members of the population have a great deal of difficulty in presenting themselves and their cases in 'official' venues.

\section{References}

Code, Lorraine. 1991. What Can She Know? Cornell University Press, Ithaca, NY.

Friedman, Marilyn. 1987. "Beyond Caring: The Demoralization of Gender", in Science, $\mathrm{MO}$ rality \& Feminist Theory, M. Hanen \& Kai Nielsen, eds. Canadian Journal of Philosophy, Supplementary Volume 13. The University of Calgary Press. Calgary, Alberta.

Gilbert, Michael A. 1994, "Multi-Modal Argumentation". Philosophy of the Social Sciences. $24: 2$.

Gilligan, Carol. 1982. In A Different Voice. Harvard University Press, Cambridge.

Grice, Paul. 1975. "Logic \& Conversation," in Studies in the Way of Words. Harvard University Press, Canbridge, MA (orig., 1975).

Hawkesworth, Mary E. 1987. "Feminist Epistemology: A Survey of the Field". Women \& Politics. 7:3:115-127.

Lakoff, Robin T. 1990. Talking Power: The Politics of Language. Basic Books, NY.

Legge, Nancy J.. 1992. "What Did You Mean By That?": The Function of Perceptions in Interpersonal Argument". Argumentation and Advocacy. 29:2:41-60.

Nye, Adrea. 1990. Words of Power. Routledge, New York.
Perelman, Ch. \& Olbrechts-Tyteca, L. 1969. The New Rhetoric. University of Notre Dame Press, Notre Dame, IN [orig Fr. 1958].

Tannen, Deborah. 1984. Conversational Style: Analyzing Talk Among Friends. Ablex, NJ.

Tannen, D. 1990. You Just Don't Understand. Ballantine, NY.

Tarski, Alfred. 1965. Introduction to Logic. Galaxy, New York. [orig. 1941].

Tronto, Joan C. 1987. "Beyond Gender Difference to a Theory of Care." Signs. 12:4:644663.

Walton, Douglas N. 1989. "Dialogue Theory for Critical Thinking". Argumentation. V. 3, nr. 2.

Warren, Karen. 1988. "Critical Thinking and Feminism". Informal Logic. Vol. X, No.1.

Willard, Charles. 1989. A Theory of Argumentation. University of Alabama Press, Tuscaloosa.

MICHAEL A. GILBERT

DEPARTMENT OF PHILOSOPHY

YORK UNIVERSITY

4700 KEELE STREET

NORTH YORK, ONTARIO MSJ IP3 